preparation and characterization of ferritin for electron microscopic studies.

Reviewers normally delight to irritate authors by quoting with a slightly superior air of helpfulness a list of minor misprints and misstatements. Maddeningly enough, although $I$ have hunted for something of the sort for more time than I can afford, I have failed to spot any, though I cannot believe that in a book of this size there are not a few.

The price is rather shattering, though it does not sound so much when quoted as 30 dollars. Despite this the book is absolutely essential as a bench book for any laboratory doing fundamental research using immunological methods and very valuable as a reference book for any biochemical or pathological laboratory where such techniques may be needed from time to time, and nowadays their use is becoming more and more fashionable all the way from botany to biophysics.

\section{Relief of Symptoms}

Walter Modell, M.D., F.A.C.P. Second edition. Pp. $354+$ index. St. Louis: The C. V. Mosby Company. London: Henry Kimpton. 196r. 86s.

In principle, a volume devoted to the relief of symptoms is admirable, and the best way to discuss its value is to put it into daily use, turning constantly to it for guidance. Indeed, it is the author's declared intention that it should be a practical guide to the problems of providing the patient with relief from distress. In order to succeed, such a guide and companion should have a first-rate index, the minimum of verbosity, skilfully constructed charts to equate various symptoms with their means of relief, and it should, of course, be up to date. This book is deficient in some measure in all these respects. The relief of liver dysfunction in the chapter on unconsciousness is dismissed in the fullblown sentence 'Diet and nutrition would seem to have a bearing, but there is no uniformity of opinion on which elements in diet spare the liver, which support it, and which stimulate it, and it is certain that no matter how one feeds the patient, orally or parenterally, he will be going counter to the advice of one expert or another'. It is well known that methyltestosterone and norethandrolone can provide dramatic relief of the intolerable pruritus associated with jaundice, but this does not appear to be the author's experience. Those who would wish to consult the book for advice in the management of one of the most painful conditions of man, orchitis, would do so in vain; neither is it possible to find the relief of post-herpetic neuralgia, renal or biliary colic, or photophobia and blurred vision due to uveitis. It is possible that the principles enunciated under the long chapter on pain are intended to cover all such contingencies. Spironolactone is mentioned in one sentence and no reference is made of its combined use with chlorothiazide for the relief of resistant œdema.

With a less discursive style of writing it could be made a more comprehensive, shorter and less expensive book to cover one of the most important aspects of medicine.

\section{Uveitis and Toxoplasmosis}

E. S. Perkins, Ph.D., M.D., F.R.C.S. Pp. vi +142 + index, illustrated. London: J. \& A. Churchill. 1961. 30s.

Professor Sorsby has estimated that uveitis is the cause of blindness in $2.5 \%$ of all blind persons in England and in $8.3 \%$ of those in the fourth decade.

During the last few years a special Uveitis Clinic in the Institute of Ophthalmology, London, has been accumulating data on the problem, and its results are now reported in detail. The analysis is based on the case records of 1,718 patients, most of whom have been referred to this special clinic from the out-patients' clinics of Moorfields Hospital. The material is classified into anterior, posterior and generalized uveitis and further subdivided into acute and chronic. The cause of the inflammation in each of these categories is analysed and certain generalizations emerge. Acute anterior and generalized uveitis are associated with chronic prostatitis, Reiter's syndrome, ankylosing spondylitis, sacro-iliitis and plantar fasciitis; chronic anterior uveitis is associated with heterochromic cyclitis; and toxoplasmosis appears to be the commonest cause of acute posterior uveitis. Sarcoidosis seems to be sprinkled throughout most groups; it comprises $3.2 \%$ of the whole series, but its incidence varies from I I \% of patients with chronic generalized uveitis to $1 \%$ of women or nil in men with chronic posterior uveitis. In most instances its clinical appearance is not characteristic, and the diagnosis of ocular sarcoidosis is established by evidence of the disease elsewhere, chest radiographic abnormalities, and by means of the Kveim test. The diagnosis of toxoplas mic uveitis was likewise indistinct until the present survey, but largely as a result of the author's pioneer work it is now clinically recognizable as a focal choroiditis involving the posterior half of the fundus, particularly near the disc, the macula and the main retinal vessels.

It is depressing to realize our ignorance concerning the atiology of uveitis. The results of this survey emphasize present limitations of knowledge and point the way to further studies, including the currently fashionable concept of auto-immunity. It is hoped that further investigations will be planned and executed in the same admirable manner as the present survey.

This monograph is essential reading for all postgraduate students in ophthalmology, and is also strongly recommended to all general physicians since uveitis is but one facet of a general disease.

\section{Psychosomatic Aspects of Pædiatrics}

Study Group of the Society for Psychosomatic Research held at the Royal College of Physicians in May, 1959. Edited by RoNALD MAcKEITH and Joseph SANDler. Pp. xiii + r 55. Oxford, London,

New York and Paris: Pergamon Press. I96r. 50s.

This book should be carefully studied by all children's doctors who, to use contemporary jargon, are psychiatrically orientated. Today, as the incidence of organic disease in the young declines, there is a growing awareness amongst pædiatricians of the relatively increasing role played by emotional factors in the causation of children's illnesses. At the same time there must often be a feeling of inadequacy on the physician's part when dealing with such cases because past medical training, with its scant regard for the psychological implications of ill health, has left many of the present generation of doctors ill equipped to deal with psychosomatic problems. Doubtless, Ronald MacKeith and Joseph Sandler, the organizers of the Study Group and co-editors of this report, had all this very much in mind when they conceived the idea of this meeting, arranged an outstanding programme and invited an audience predominantly composed of children's specialists.

Of particular interest to the clinician will be the papers on constipation and encopresis and on recurrent pains in childhood, the lucid account of identification by Sandler and the chapter reporting the sessions at which Miss Anna Freud answered brilliantly a wide range of questions from the pædiatricians in the audience. Other matters discussed and recorded in this 